\title{
Intravesical Radiofrequency-Induced Chemohyperthermia for Carcinoma in Situ of the Urinary Bladder: A Retrospective Multicentre Study
}

\author{
F. Johannes P. van Valenberg ${ }^{\mathrm{a}, *}$, Amir Kajtazovic $^{\mathrm{a}}$, Giorgio Canepa ${ }^{\mathrm{b}}$, Gerson Lüdecke $^{\mathrm{c}}$, \\ Jill-Isabel Kilb ${ }^{\mathrm{c}}$, Katja K. H. Aben ${ }^{\mathrm{d}, \mathrm{e}}$, Ofer Nativ ${ }^{\mathrm{f}}$, Sanjeev Madaan ${ }^{\mathrm{g}}$, Benjamin Ayres ${ }^{\mathrm{g}}$, \\ Rami Issa ${ }^{\mathrm{h}}$ and J. Alfred Witjes ${ }^{\mathrm{a}}$ \\ ${ }^{a}$ Department of Urology, Radboud University Medical Center, Nijmegen, The Netherlands \\ ${ }^{\mathrm{b}}$ Ente Ospedaliero Ospedali Galliera, Genova, Italy \\ ${ }^{\mathrm{c}}$ University Clinics Giessen and Marburg GmbH, Location Giessen, Justus-Liebig University Giessen, Germany \\ ${ }^{\mathrm{d}}$ Radboud University Medical Center, Radboud Institute for Health Sciences, Nijmegen, The Netherlands \\ ${ }^{\mathrm{e}}$ Department of Research, Netherlands Comprehensive Cancer Organisation, Utrecht, The Netherlands \\ ${ }^{\mathrm{f}}$ Bnai-Zion Hospital, Haifa, Israel \\ ${ }^{\mathrm{g}}$ Darent Valley Hospital, Dartford, UK \\ ${ }^{\mathrm{h}}$ St. George's Hospital, London, UK
}

Received 4 June 2018

Accepted 7 August 2018

\begin{abstract}
.
Objective: To examine the effect of intravesical radiofrequency-induced chemohyperthermia (RF-CHT) in carcinoma in-situ (CIS) patients overall and split according to previously received therapy.

Methods: CIS patients that underwent an induction and maintenance phase of $\geq 6$ RF-CHT instillations, and had either pathology or cystoscopy plus cytology available at 6 months of follow-up were retrospectively included. Complete response (CR), recurrences, cystectomy-free rate, overall survival (OS), and adverse events were evaluated. Analysis was performed for overall, bacillus Calmette-Guérin (BCG)-unresponsive, other BCG-treated, and treatment naïve patients.

Results: Patients $(n=150)$ had a mean of $17.5,9.2$, or 0 previous BCG instillations in the BCG-unresponsive $(n=50)$, other BCG-treated ( $n=46$, missing $n=4)$, and treatment naïve groups $(n=47$, missing $n=3)$, respectively. After 6 months, a CR of $46.0 \%, 71.7 \%$, and $83.0 \%$ was found $(p<0.001)$. Subsequent 2 -year recurrence rates were $17.4 \%, 27.3 \%$, and $12.8 \%$, respectively. The overall cystectomy-free rate and OS at mean follow-up (35.8 months) were 78.5\% and 78.0\%, respectively. These were $71.4 \%$ vs. $84.1 \%$ vs. $86.7 \%$ (cystectomy-free rate, $p=0.006$ ) and $76.0 \%$ vs. $69.6 \%$ vs. $87.2 \%$ (OS, $p=0.06$ ) for BCG-unresponsive vs. other BCG-treated vs. treatment naïve patients. Progression to muscle-invasive disease was seen in $13.3 \%$ of patients. Patients stopped induction or maintenance RF-CHT instillations due to adverse events in respectively $13.4 \%$ and $17.8 \%$.
\end{abstract}

\footnotetext{
*Correspondence to: F. Johannes P. van Valenberg, Radboudumc, Geert Grooteplein 26-28, Internal postal code 267, P.O. Box 9101, 6500 HB Nijmegen, The Netherlands. Tel.: +0031 24
} 
Conclusions: Intravesical RF-CHT showed good results in both treatment naïve and BCG-treated CIS patients, avoiding the need for cystectomy in $78.5 \%$ of cases for at least 3 years with a modest risk of progression. Thus, RF-CHT proves an alternative to cystectomy in selected high-risk patients.

Keywords: Hyperthermia, radiofrequency, urinary bladder neoplasms, intravesical therapy, carcinoma in situ, bacillus Calmette-Guérin

\section{INTRODUCTION}

Urothelial cell carcinoma in-situ (CIS) of the urinary bladder is a relatively uncommon finding in patients with non-muscle-invasive bladder cancer (NMIBC), with less than $10 \%$ of cases having associated CIS [1]. However, due to the high number of patients with bladder cancer and its high recurrence rate, urothelial CIS is still associated with a significant prevalence $[2,3]$. Urothelial CIS is a nonpapillary high-grade form of NMIBC. Unlike most intraepithelial carcinomas in other organs, CIS of the urinary tract is - with a hazard ratio of $1.46-$ at high risk of progression to muscle-invasive disease (MIBC), with a subsequent risk of metastasis and mortality $[4,5]$. Without treatment, over $50 \%$ of patients progress to MIBC [6].

To prevent progression to MIBC and facilitate bladder preservation in patients with CIS, an intensive intravesical management is advised by the urological guidelines [7, 8]. The current gold standard for CIS consists of full dose bacillus Calmette-Guérin (BCG) immunotherapy in a 3-year induction plus maintenance scheme according to the SWOG protocol $[9,10]$. This results in a complete response (CR) rate of $70-75 \%$ after 3 months [11]. However, a significant number of patients eventually prove to be BCG-unresponsive or intolerant [12-15]. Two potential issues with BCG are the adverse events associated with this viable, although weakened, mycobacterium, and the fact that availability of BCG is dependent on growth of the mycobacterium under highly controlled circumstances which can be achieved by a limited number of manufacturers, making BCG susceptible to scarcity.

Alternative bladder-sparing therapies to replace BCG immunotherapy are being investigated [16]. An effective option is to combine intravesical chemotherapy with mild hyperthermia of the bladder mucosa $[17,18]$. A recent randomized clinical trial evaluated the efficacy of intravesical radiofrequencyinduced chemohyperthermia (RF-CHT) vs. BCG immunotherapy in intermediate-high risk NMIBC patients, showing a 2-year recurrence free survival (RFS) rate of $81.8 \%$ and $64.8 \%$, respectively, and a progression rate of $<2 \%$ in both groups [19]. However, this study included only 43 CIS patients who all were BCG-naïve. A previous exploratory retrospective study of RF-CHT efficacy in 49 CIS patients, of which 15 were BCG-naïve, showed a 3-months CR rate of $92 \%$ which remained $51 \%$ after 2 years [20]. Nonetheless, evidence on RF-CHT efficacy in CIS patients is limited, specifically in those who have been previously treated with BCG. In these patients, RFCHT might be considered prior to radical cystectomy provided that its efficacy is sufficient [21].

We aimed to examine the effect of intravesical RFCHT in CIS patients who were either treatment naïve, or who were previously treated with or unresponsive to BCG immunotherapy.

\section{PATIENTS AND METHODS}

\section{Patient selection}

Patients with histologically proven CIS, with or without coexisting papillary Ta/T1 NMIBC tumor(s), who had been treated with RF-CHT using mitomycin C (MMC) were retrospectively collected from six international centres between January 2000 and December 2016. Of these, those who had received $\geq 6$ RF-CHT instillations and had either pathology or the combination of cytology and cystoscopy results available at 6 months (range 5-9 months) of followup were eligible for the efficacy analysis. Efficacy analysis was additionally performed separately for treatment naive patients, for patients that were BCGunresponsive, and for the remaining BCG-treated group, i.e. patients who were BCG-intolerant or did not meet the definition of BCG-unresponsive disease due to late disease recurrence or due to an inadequate BCG regimen. Treatment naïve patients generally had received RF-CHT due to unavailability of BCG, or within a previous different study protocol. BCGunresponsive disease was defined as a persistence or recurrence of CIS after an adequate BCG regimen 
was initiated, or relapse of CIS within 6 months of their last intravesical treatment with BCG despite an initial complete response to BCG [16, 22]. An adequate $\mathrm{BCG}$ regimen was defined as at least 2 courses of BCG where the first course (induction) must have included at least 5 out of 6 weekly treatments and the second course may have included a re-induction (5 out of 6 treatments) or maintenance of at least 2 out of 3 treatments.

For evaluation of treatment tolerability all patients who had received any RF-CHT instillations were used.

Due to the retrospective nature, no approval of any ethical committee was needed.

\section{Outcomes}

The primary endpoint was CR after 6 months since start of RF-CHT, defined as absence of CIS, papillary high-grade (HG) tumor, stage $\mathrm{T} 1$ tumor, or extra-vesical evidence of urothelial carcinoma. To be considered a complete responder, a patient had to have a negative result as proven by histopathologic examination or by cystoscopy and urine cytology. Exceptions to this definition included patients with only upper tract involvement, or patients with a Talow grade (TaLG) recurrence only since this was regarded as having a clinical benefit from therapy. These patients were evaluated as responders.

As secondary end-points, both the 2-year recurrence rate and recurrence free survival (RFS) after $\mathrm{CR}$, as confirmed by pathology or cytology plus cystoscopy, were evaluated. Additionally, progression rate, overall survival (OS), cystectomy-free survival, and treatment tolerability were assessed at final follow-up. Progression was defined as development of MIBC with or without lymph node or distant metastasis at final follow-up. Treatment tolerability was evaluated by assessment of the drop-out rate due to adverse event which could include spasms, urgency or frequency between or during sessions, or allergic reactions to the instilled drug.

To investigate whether additional RF-CHT instillations were of value in treatment of CIS, we also evaluated CR rates after further maintenance RF-CHT instillations with its associated 2-year recurrence rate.

\section{Treatment}

Radiofrequency-induced chemohyperthermia was given using the Synergo ${ }^{\circledR}$ SB-TS 101 system
[18]. This system consists of a $915 \mathrm{MHz}$ intravesical microwave applicator located in a specifically designed catheter that delivers mild hyperthermia $\left(40.5\right.$ to $\left.44^{\circ} \mathrm{C}\right)$ to the bladder wall via direct nonionizing irradiation. Temperatures were monitored by two urethral and three mucosal thermocouples integrated in the 20 French catheter. To avoid urethral overheating and disintegration of the chemotherapeutic agent, the solution was continuously recirculated and cooled. Typically, MMC was used in a dose of $40 \mathrm{mg} / 50 \mathrm{ml}$. The instilled solution was replaced by a fresh identical solution after $30 \mathrm{~min}$ (a total of $80 \mathrm{mg}$ MMC in $1 \mathrm{~h}$ ). Patients were treated weekly for 4 to 8 weeks depending on the planned induction schedule, which was followed by maintenance instillations (one instillation every $4-8$ weeks). Schedules slightly differed per centre.

\section{Analyses}

For demographics, means with standard deviations (SD) or standard error of the mean (SEM) were calculated for continuous variables. For dichotomous variables, percentages were determined.

Complete response was assessed and additionally compared between BCG-unresponsive, other BCG-treated, and treatment naive patients using the chi-square test. Absolute recurrence rates were assessed. Kaplan-Meier analysis with Mantel-Cox $\log$ rank tests was used for the recurrence-free, overall and cystectomy-free survival evaluation. Additionally, relative survival was determined, defined as the ratio of overall survival of the patients by the survival of a similar general Dutch population matched on age, sex and calendar year and can be used as an approximation of cancer-specific survival.

Analyses were performed using SPSS software, version 22 , with a two-sided $p<0.05$ considered statistically significant. For the relative survival analysis, SAS version 9.4 (SAS Institute Inc., Cary, NC, USA) was used.

\section{RESULTS}

\section{Patients}

In total, 270 CIS patients treated with RFCHT were identified. Of these, 236 patients had received $\geq 6$ RF-CHT instillations, whereas pathology or cystoscopy and cytology results at 6 months of follow-up were available in 150 patients. Exclusion of the 86 patients was solely based on this 
Table 1

Demographics

\begin{tabular}{|c|c|c|c|c|}
\hline & $\begin{array}{l}\text { Overall } \\
\text { CIS }\end{array}$ & $\begin{array}{c}\text { BCG- } \\
\text { unresponsive CIS }\end{array}$ & $\begin{array}{l}\text { Other BCG- } \\
\text { treated CIS }\end{array}$ & $\begin{array}{c}\text { Treatment naïve } \\
\text { CIS }\end{array}$ \\
\hline $\bar{n}$ & 150 & 50 & 46 missing $n=4$ & 47 missing $n=3$ \\
\hline \multicolumn{5}{|l|}{ Sex } \\
\hline Male $n(\%)$ & $123(82.0)$ & $38(76.0)$ & $39(84.8)$ & $40(85.1)$ \\
\hline Female $n(\%)$ & $27(18.0)$ & $12(24.0)$ & $7(15.2)$ & $7(14.9)$ \\
\hline Mean age at start of RF-CHT $y(\mathrm{SD})$ & $69.4(9.52)$ & $69.4(9.84)$ & $72.2(9.00)$ & $67.2(9.08)$ \\
\hline \multicolumn{5}{|l|}{ General history $n(\%)$} \\
\hline $\mathrm{BPH}$ & $25(16.7)$ & $7(14.0)$ & $9(19.6)$ & $9(19.1)$ \\
\hline Prostate cancer & $14(9.3)$ & $4(8.0)$ & $7(15.2)$ & $3(6.4)$ \\
\hline Urethral stricture & $4(2.6)$ & $0(0.0)$ & $2(4.3)$ & $2(4.3)$ \\
\hline Bladder diverticulum & $2(1.3)$ & $1(2.0)$ & $1(2.2)$ & $0(0.0)$ \\
\hline \multicolumn{5}{|l|}{ Worst stage in NMIBC history ${ }^{\dagger} n(\%)$} \\
\hline $\mathrm{Ta}$ & $11(7.3)$ & $3(6.0)$ & $4(8.7)$ & $4(8.5)$ \\
\hline $\mathrm{T} 1$ & $24(16.0)$ & $4(8.0)$ & $7(15.2)$ & $13(27.7)$ \\
\hline CIS & $63(42.0)$ & $28(56.0)$ & $14(30.4)$ & $18(38.3)$ \\
\hline $\mathrm{Ta}+\mathrm{CIS}$ & $20(13.3)$ & $8(16.0)$ & $8(17.4)$ & $2(4.3)$ \\
\hline $\mathrm{T} 1+\mathrm{CIS}$ & $32(21.3)$ & $7(14.0)$ & $13(28.3)$ & $10(21.3)$ \\
\hline \multicolumn{5}{|l|}{ Worst grade in NMIBC history $^{\dagger} n(\%)$} \\
\hline G1 & $7(4.7)$ & $3(6.0)$ & $1(2.2)$ & $3(6.4)$ \\
\hline $\mathrm{G} 2$ & $8(5.3)$ & $2(4.0)$ & $1(2.2)$ & $4(8.5)$ \\
\hline G3 & $135(90.0)$ & $45(90.0)$ & $44(95.7)$ & $40(85.1)$ \\
\hline \multicolumn{5}{|l|}{ Pathology before start of RF-CHT $n(\%)$} \\
\hline CIS only & $89(59.3)$ & $39(78.0)$ & $20(43.5)$ & $27(57.4)$ \\
\hline CIS + TaLG & $7(4.7)$ & $1(2.0)$ & $3(6.5)$ & $2(4.3)$ \\
\hline $\mathrm{CIS}+\mathrm{TaHG}$ & $20(13.3)$ & $6(12.0)$ & $10(21.7)$ & $3(6.4)$ \\
\hline $\mathrm{CIS}+\mathrm{T} 1 \mathrm{LG}$ & $1(0.7)$ & $1(2.0)$ & $0(0.0)$ & $0(0.0)$ \\
\hline $\mathrm{CIS}+\mathrm{T} 1 \mathrm{HG}$ & $33(22.0)$ & $3(6.0)$ & $13(28.3)$ & $15(31.9)$ \\
\hline BCG instillations before RF-CHT mean (SEM)* & $9.1(0.76)$ & $17.5(0.94)$ & $9.2(0.98)$ & N/A N/A \\
\hline TURBTs before RF-CHT mean (SEM) & $2.3(0.10)$ & $2.6(0.15)$ & $2.4(0.16)$ & $2.1(0.16)$ \\
\hline RF-CHT instillations at CR evaluation mean $(\mathrm{SEM})^{\ddagger *}$ & $8.2(0.13)$ & $7.6(0.15)$ & $8.8(0.20)$ & $8.0(0.28)$ \\
\hline
\end{tabular}

BCG, bacille Calmette-Guérin; BPH, benign prostate hypertrophia; CIS, carcinoma in-situ; CR, complete response; HG, high grade; LG, low grade; N/A, not applicable; NMIBC, non-muscle invasive bladder cancer; RF-CHT, radiofrequency-induced chemohyperthermia; SD, standard deviation; SEM, standard error of the mean; TURBT, trans-urethral resection of bladder tumor or biopsies. *Values differ significantly between each group. ${ }^{\dagger}$ Excluding the pathology stage or grade for which RF-CHT was started. ${ }^{\ddagger}$ Calculation for 6 -months CR evaluation (range 5-9 months). For CR evaluation after additional maintenance RF-CHT instillations, the mean amount of instillations was 10.3 (SEM 0.20), 9.8 (SEM 0.27), 10.0 (0.25), and 11.0 (SEM 0.43), respectively, and did not differ significantly between groups.

criterion. Patient demographics of the included group of patients $(n=150)$ - which were used for the efficacy analysis - are depicted in Table 1, and were similar to the total group of patients who had received $\geq 6$ RF-CHT instillations. Mean age was 69.4 years, with a male-to-female ratio of 4.6 to 1 . Patients received an average of 9.1 previous BCG-instillations and were treated with a mean of 8.2 RF-CHT instillations at CR assessment, with a dose of twice $40 \mathrm{mg}(n=119,79.3 \%)$ or, less frequently, twice $20 \mathrm{mg} \mathrm{MMC}(n=31,20.7 \%)$. Of all 150 patients, $76.7 \%$ had recurrent CIS with or without concomitant papillary tumor as a worst stage in their history, whereas the other $23.3 \%$ of patients had primary CIS.

The mean time of follow-up for the overall group ( $n=150)$, BCG-unresponsive patients $(n=50)$, other BCG-treated patients $(n=46$, missing $n=4)$, and treatment naïve patients ( $n=47$, missing $n=3$ ) was 35.8 months, 27.5 months, 38.5 months, and 40.6 months, respectively.

Efficacy

CR after 6 months was $66.2 \%$ (Table 2). For BCGunresponsive patients the $\mathrm{CR}$ was $46.0 \%$, which differed significantly from other BCG-treated and treatment naïve CIS patients $(71.7 \%$ and $83.0 \%$ respectively, $p<0.001$ ). In patients with a CR, the subsequent recurrence rate and RFS after 2 years of follow-up were $18.8 \%$ and $74.5 \%$ for the overall group and did not differ significantly between any of the groups (Table 2, Fig. 1). CR rate increased with an increased number of RF-CHT instillations from $66.2 \%$ to $77.1 \%$ for the overall group after respectively a mean amount of 8.2 and 10.3 instillations. For 
Table 2

Complete response rates at 6 months from start of RF-CHT with corresponding 2-year recurrence rates and recurrence free survival

\begin{tabular}{lcccc}
\hline & $\begin{array}{c}\text { Overall } \\
\text { CIS }\end{array}$ & $\begin{array}{c}\text { BCG- } \\
\text { unresponsive CIS }\end{array}$ & $\begin{array}{c}\text { Other BCG- } \\
\text { treated CIS }\end{array}$ & $\begin{array}{c}\text { Treatment naïve } \\
\text { CIS }\end{array}$ \\
\hline$n \quad$ & 143 (missing $n=7)$ & 50 & $46(\operatorname{missing} n=4)$ & $47(\operatorname{missing} n=3)$ \\
$\begin{array}{l}\text { CR at } 6 \text { months from start } \\
\text { RF-CHT } n \text { (\%) }\end{array}$ & $96(66.2)$ & $23(46.0)^{*}$ & $33(71.7)^{*}$ & $39(83.0)^{*}$ \\
$\begin{array}{l}\text { 2-year recurrence rate } n \text { (\% of } \\
\text { patients with CR) }\end{array}$ & $18(18.8)$ & $4(17.4)$ & $9(27.3)$ & $5(12.8)$ \\
$\begin{array}{l}\text { 2-year RFS cumulative surviving } \\
\text { proportion in \% }\end{array}$ & 74.5 & 68.9 & 68.6 & 83.6 \\
\hline
\end{tabular}

BCG, bacille Calmette-Guérin; CIS, carcinoma in-situ; CR, complete response; RF-CHT, radiofrequency-induced chemohyperthermia; RFS, recurrence free survival. *significant difference between BCG-unresponsive, other BCG-treated, and treatment naïve CIS patients, $p<0.001$.

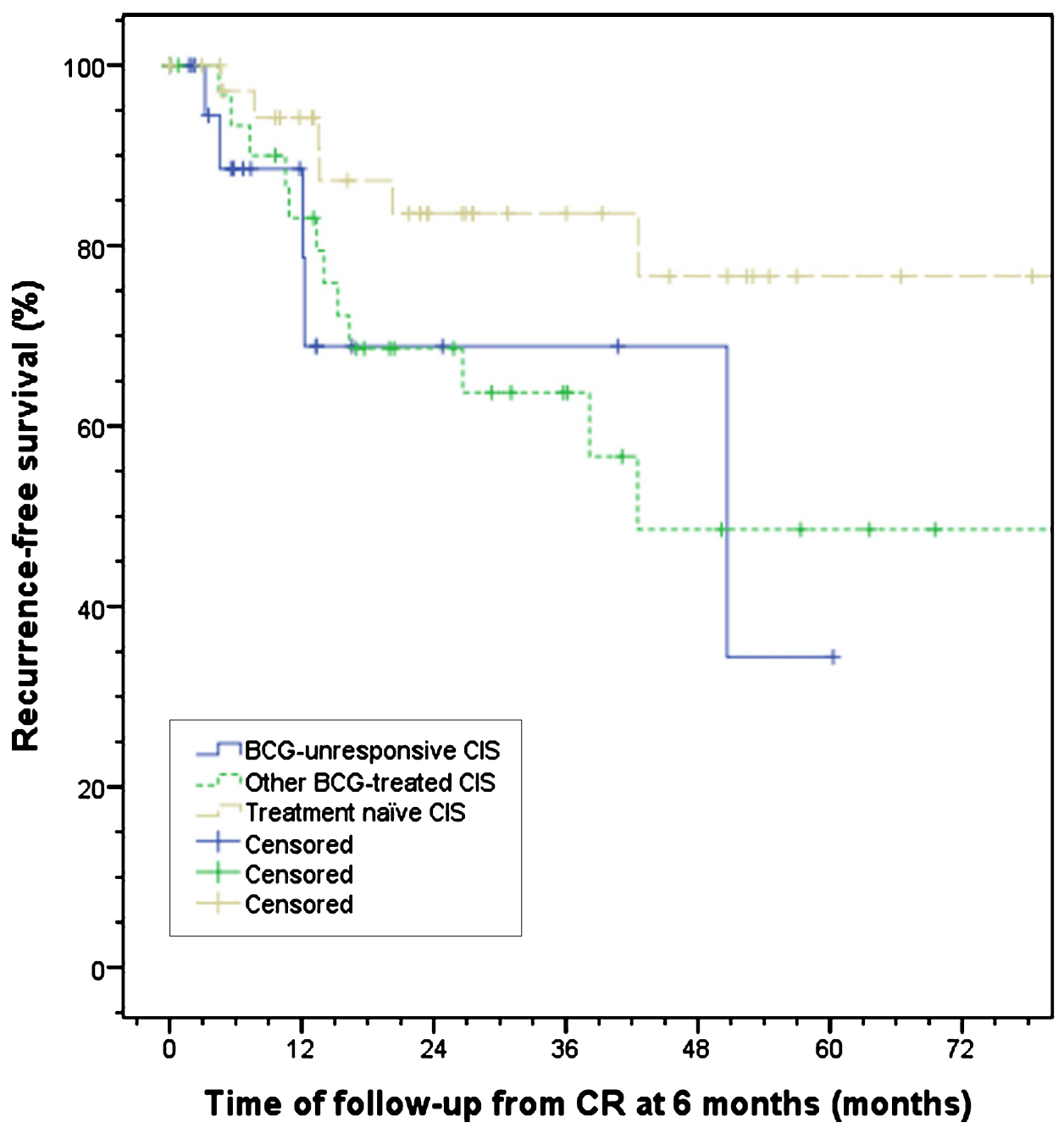

Fig. 1. Recurrence-free survival after RF-CHT split by treatment history. No significant difference between BCG-unresponsive, other BCGtreated, and treatment naïve CIS patients was observed, $p=0.08$. BCG, bacillus Calmette-Guérin; CIS, carcinoma in situ; CR, complete response; RF-CHT, radiofrequency-induced chemohyperthermia.

BCG-unresponsive patients, CR rate increased from $46.0 \%$ to $57.6 \%$ after a mean amount of 7.6 and 9.8 instillations, respectively (Table 3). Patients treated with a dose of $40 \mathrm{mg}$ had a trend towards higher CR rates compared with a dose of $20 \mathrm{mg}$, although not significant $(69.5 \%$ vs. $51.6 \%, p=0.06)$. 
Table 3

Complete response rates after additional maintenance instillations with corresponding 2-year recurrence rates and recurrence free survival

\begin{tabular}{|c|c|c|c|c|}
\hline & $\begin{array}{l}\text { Overall } \\
\text { CIS }\end{array}$ & $\begin{array}{c}\text { BCG- } \\
\text { unresponsive CIS }\end{array}$ & $\begin{array}{l}\text { Other BCG- } \\
\text { treated CIS }\end{array}$ & $\begin{array}{l}\text { Treatment naïve } \\
\text { CIS }\end{array}$ \\
\hline$\overline{n^{\dagger}}$ & 131 & 33 & 57 & 41 \\
\hline $\begin{array}{l}\mathrm{CR} \text { after additional maintenance } \\
\text { instillations } \mathrm{s}^{\ddagger} n(\%)\end{array}$ & $101(77.1)$ & $19(57.6)^{*}$ & $45(78.9)^{*}$ & $37(90.2)^{*}$ \\
\hline $\begin{array}{l}\text { 2-year recurrence rate } n \text { (\% of patients with } \\
\text { CR) }\end{array}$ & $20(19.4)$ & $5(26.3)$ & $10(22.2)$ & $5(13.5)$ \\
\hline $\begin{array}{l}\text { 2-year RFS cumulative surviving proportion } \\
\text { in } \%\end{array}$ & 75.2 & 59.9 & 73.7 & 82.8 \\
\hline
\end{tabular}

BCG, bacille Calmette-Guérin; CIS, carcinoma in-situ; CR, complete response; RF-CHT, radiofrequency-induced chemohyperthermia; RFS, recurrence free survival. ${ }^{\dagger}$ The $n$ differs with the $\mathrm{CR}$ assessment at 6 months calculation due to missing data on CR in the different groups. ${ }^{\ddagger}$ On average, an additional amount of two RF-CHT instillations had been received as compared to the CR assessment at 6 months from start of RF-CHT. Patient group was not identical to the CR group at 6 months. *significant difference between BCG-unresponsive, other BCG-treated, and treatment naïve CIS patients, $p=0.002$.

In $13.3 \%$ of patients, progression to MIBC with or without lymph node or distant metastasis at final follow-up was seen, consisting of $16.0 \%$ in BCG-unresponsive, $13.0 \%$ in other BCG-treated, and $10.6 \%$ in treatment naïve CIS patients $(p=0.74)$.

The bladder preservation rate at final followup was $78.5 \%$ with a mean cystectomy-free time of 99.9 months (95\%-CI 86.7-113.1). For BCGunresponsive patients these were $71.4 \%$ and 45.2 months (95\%-CI 35.7-54.7), respectively, and differed significantly between BCG-unresponsive and both other BCG-treated and treatment naive patients ( $p=0.006$, Fig. 2, Table 4).

Patients had an overall survival of $78.0 \%$ at final follow-up (Table 4). The mean survival time was 89.5 months (95\%-CI 74.7-104.8). For BCGunresponsive patients these were $76.0 \%$ and 79.7 months (95\%-CI 65.2-94.3), respectively (Fig. 3). No statistical difference between the groups was found, although a trend towards a significant difference between other BCG-treated and treatment naive patients was observed $(p=0.06)$. The relative survival, acting as an approximation of the cancerspecific survival, was $89 \%$ after 3 years and $84 \%$ after 5 years of follow-up, although $95 \%$ confidence intervals overlapped substantially between the actually observed overall survival and the relative survival. For Dutch patients only, relative survival was $82 \%$ after 3 years and $86 \%$ after 5 years of follow-up (Fig. 4).

If CIS patients who had at least six RF-CHT instillations were used for the efficacy analysis $(n=236)$, thus abandoning the more strict inclusion criterion of either pathology or cystoscopy plus cytology availability at follow-up, progression rate, cystectomy-free rate, and overall survival rate did not substantially differ from the group analyzed above. This analysis thus confirms that our data are consistent also within a broader inclusion of patients and unlikely subject to significant selection bias.

\section{Treatment tolerability}

In total, $13.4 \%$ and $17.8 \%$ of patients receiving any amount of RF-CHT instillations eventually had to stop either induction or maintenance RF-CHT instillations due to adverse events. Pooled for both induction and maintenance, these adverse events consisted of pain or spasms during an instillation in $7.8 \%$, allergy in $8.2 \%$, and frequency or urge between instillations in $7.5 \%$ of total patients.

\section{DISCUSSION}

CIS is at risk for progression to muscle-invasive disease. In cases not responding or intolerant to BCG immunotherapy, urological guidelines advise a radical cystectomy. Due to its associated morbidity and mortality, alternatives to radical cystectomy are desired in CIS patients who no longer respond to or tolerate BCG instillations. Indeed, even in BCG naïve intermediate to high-risk NMIBC, such an alternative might be of value in light of BCG toxicity and availability.

We found that with intravesical RF-CHT, a complete response rate of $66.2 \%$ with subsequent recurrences in $18.8 \%$ after 2 years can be achieved in CIS patients. A higher amount of RF-CHT instillations further improved these figures. More interestingly, a bladder preservation rate of $78.5 \%$ after a mean follow-up of about 3 years with a $13.3 \%$ rate of disease progression was found. Also for BCGunresponsive patients - who are at the highest risk of 


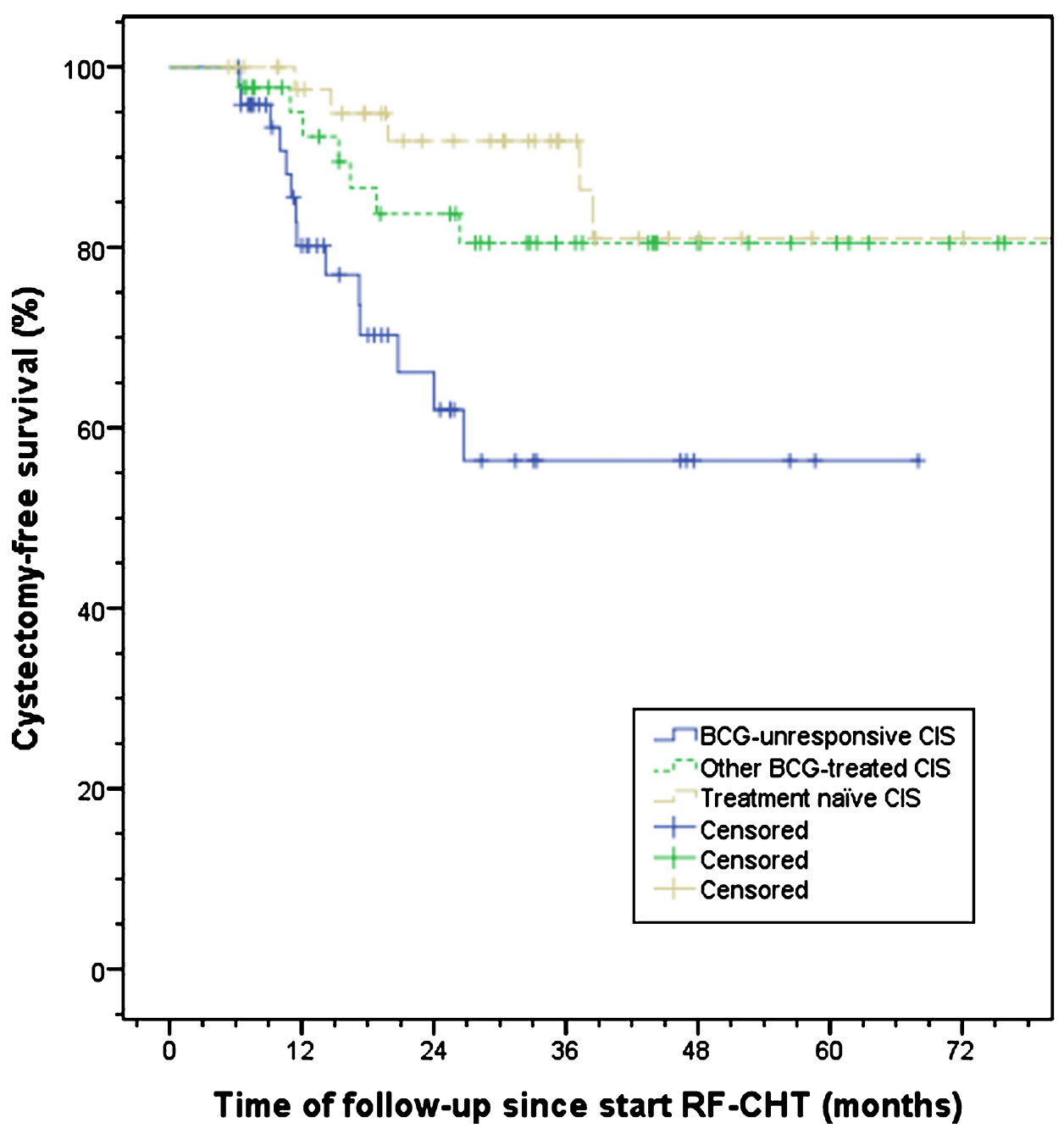

Fig. 2. Cystectomy-free survival split by treatment history. A significant difference between BCG-unresponsive, other BCG-treated, and treatment naïve CIS patients was observed, $p=0.006$. BCG, bacillus Calmette-Guérin; CIS, carcinoma in situ; RF-CHT, radiofrequencyinduced chemohyperthermia.

Table 4

Bladder preservation and overall survival rate

\begin{tabular}{|c|c|c|c|c|}
\hline & $\begin{array}{c}\text { Overall } \\
\text { CIS }^{\dagger}\end{array}$ & $\begin{array}{c}\text { BCG- } \\
\text { unresponsive CIS } \\
\end{array}$ & $\begin{array}{l}\text { Other BCG- } \\
\text { treated CIS }\end{array}$ & $\begin{array}{c}\text { Treatment naïve } \\
\text { CIS II }\end{array}$ \\
\hline$n$ & 144 (missing $n=6$ ) & 49 (missing $n=1$ ) & 44 (missing $n=6$ ) & 45 (missing $n=5$ ) \\
\hline $\begin{array}{l}\text { Bladder preservation } \\
\text { rate } n(\%)\end{array}$ & $113(78.5)$ & $35(71.4)^{*}$ & $37(84.1)^{*}$ & $39(86.7)^{*}$ \\
\hline$n$ & 150 & 50 & 46 (missing $n=4$ ) & 47 (missing $n=3$ ) \\
\hline Overall survival $n(\%)$ & $117(78.0)$ & $38(76.0)$ & $32(69.6)^{* *}$ & $41(87.2)^{* *}$ \\
\hline
\end{tabular}

BCG, bacille Calmette-Guérin; CIS, carcinoma in-situ; RF-CHT, radiofrequency-induced chemohyperthermia; SEM, standard error of the mean. ${ }^{\dagger}$ mean follow-up of 35.8 months, SEM 2.18. ${ }^{\ddagger}$ mean follow-up of 27.5 months, SEM 3.01. ${ }^{\S}$ mean follow-up of 38.5 months, SEM 3.67 .

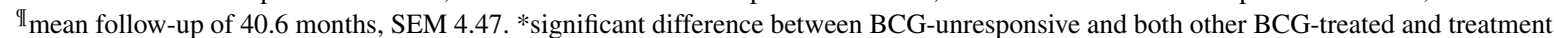
naïve CIS patients, $p=0.006$. **trend towards a significant difference between other BCG-treated and treatment naïve CIS patients, $p=0.06$.

progression - a promising bladder preservation rate of $71.4 \%$ and a disease progression rate of $16.0 \%$ was found. Thus, RF-CHT might prove to be an option in patients who are at high risk of progression and unwilling or unable to undergo a radical cystectomy. 


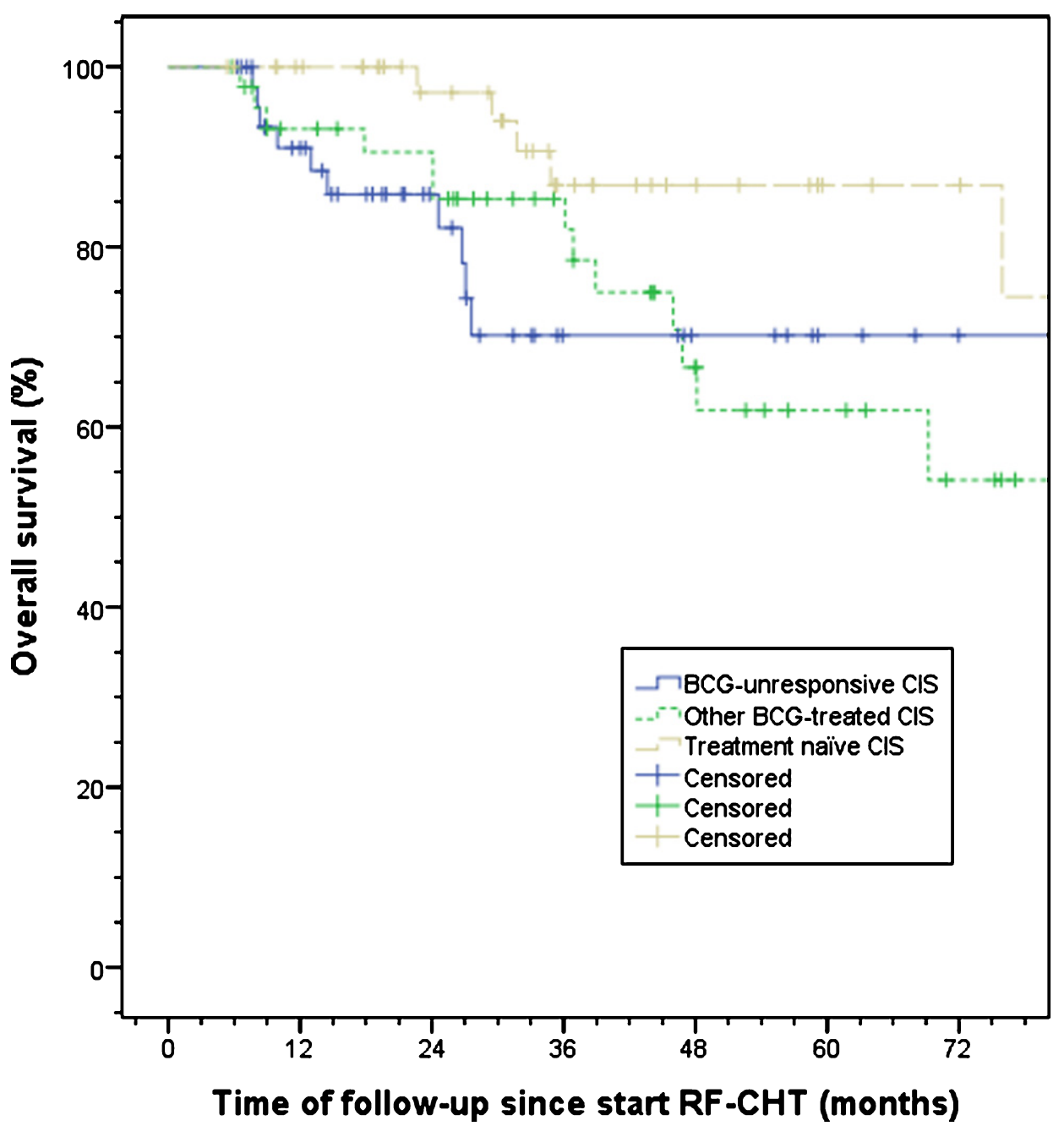

Fig. 3. Observed overall survival split by treatment history. A trend towards a significant difference between other BCG-treated and treatment naïve CIS patients was observed, $p=0.06$. BCG, bacillus Calmette-Guérin; CIS, carcinoma in situ; RF-CHT, radiofrequency-induced chemohyperthermia.

Although the current gold standard for CIS, i.e. BCG immunotherapy, has proven to be effective in high-risk NMIBC, a substantial amount of patients recur, progress, or appear intolerant for BCG [12-15]. For these patients, several alternative options to radical cystectomy are being investigated. Electromotive drug administration, in which uptake of MMC is enhanced by electrical facilitation of osmosis, has shown promising results combined with BCG vs. BCG alone, but has yet only been described in BCG-naive $\mathrm{T} 1$ patients after transurethral resection and not in BCG-unresponsive CIS patients [23]. Other options under research include photodynamic therapy which uses photo-activation of a cytotoxic agent targeted to tumor cells, chemotherapeutic agents other than the typically administered drugs like mitomycin C and epirubicin [24-28], or combinations of chemotherapeutic drugs (NCT02202772). None have yet shown sufficient efficacy to replace BCG. In future trials, a specific interest in using cytokines (NCT02773849), PD-(L)1 inhibitors (NCT02844816, NCT02625961), and deviceassisted therapies (e.g. RF-CHT, NCT03335059) is seen. To date, the most promising results in NMIBC have been achieved using RF-CHT [18, 19, 29].

This study demonstrates that RF-CHT might be a useful treatment option for patients unfit or unwilling to undergo a radical cystectomy. Apart from the good CR rate and subsequent low recurrence rate, the progression rate for overall and, in particular, 

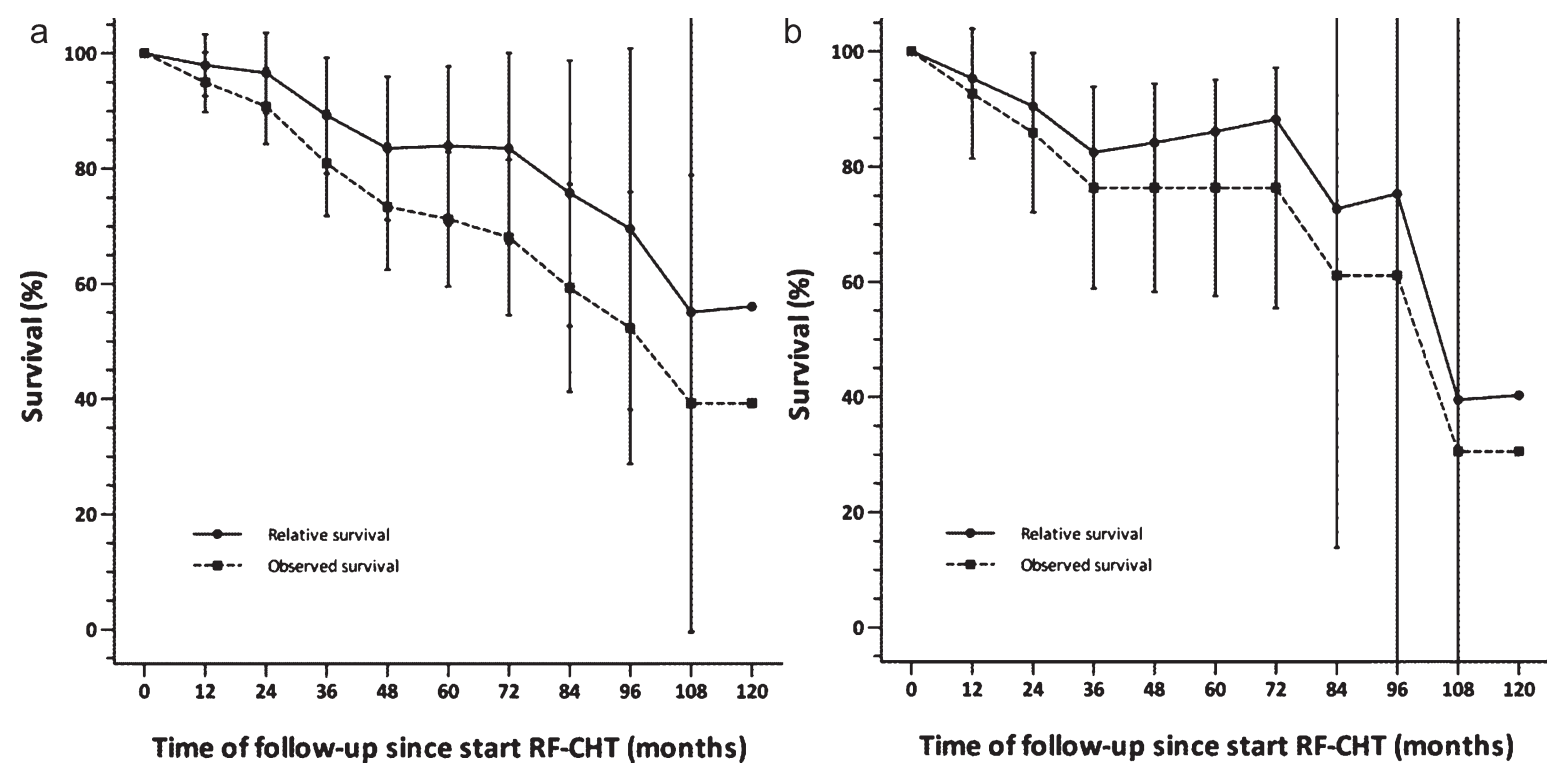

Fig. 4. Survival relative to a matched general Dutch population. Survival for a) all patients $(n=150)$, and b) Dutch patients only ( $n=58)$. Vertical bars represent $95 \%$ confidence intervals. RF-CHT, radiofrequency-induced chemohyperthermia.

BCG-unresponsive CIS patients of $13.3 \%$ and $16.0 \%$ after up to nearly 36 months compares favorable to progression rates in similar high-risk groups as reported by the CUETO group [13, 14]. Most interestingly, however, is the accomplished cystectomy-free rate of $78.5 \%$. In this group of high-risk patients, AUA and EAU guidelines advise a radical cystectomy in all patients fit enough for major surgery [7, 8]. Thus, an important finding of this alternative treatment option is the potential avoidance, or at least delay, of a cystectomy in a majority of these patients.

In addition, we found an overall absolute survival of about $71 \%$ at 5 years of follow-up (Fig. 3). The relative survival after 5 years is about $53 \%$ for all stage bladder cancer [30] and $88 \%$ for NMIBC only[source: Netherlands Cancer Registry] in Dutch bladder cancer patients. For Europe in general, the relative survival is about $68 \%$ and $88 \%$ for all stage disease and NMIBC only, respectively [31]. In this light, the relative 5-year survival of $84 \%$ in our highrisk patient cohort seemed relatively good.

Of interest is the trend towards a lower OS in other BCG-treated patients vs. treatment naïve patients. This possibly is explained by the BCG-intolerant patients in this group, who might have been more frail or might have stopped BCG more often due to comorbidity.

Although BCG-unresponsive patients had significantly worse CR $(46.0 \%, p<0.001)$ and cystectomyfree rates $(71.4 \%, p=0.006)$, OS did not differ significantly compared with the other groups. Moreover, the CR, RFS, and cystectomy-free rates still seem higher compared with other conservative therapeutic options [32] and fulfill the minimum criterion of a $30 \%$ RFS at 18 to 24 months as defined by the Food and Drug Administration and AUA for BCG-unresponsive high risk NMIBC [21]. These results reflect a substantial gain in this patient group.

One study which has previously evaluated RFCHT in CIS patients, showed better 3-months CR rates of $92 \%$ with $49 \%$ having a recurrence and $13 \%$ undergoing a cystectomy at a mean follow-up of 27 months [20]. However, this patient group was somewhat smaller $(n=49)$ and consisted of fewer BCG-treated patients $(n=34)$ of which only 17 were BCG-refractory. Another study on RF-CHT evaluated a group of patients of whom $83 \%$ had CIS, and $80 \%$ of patients were previously treated with BCG, without further information on BCG-response. After 8 weeks, a CR rate in CIS patients of $80 \%$ was found [33]. A similar rate was observed in a recent randomized controlled trial comparing BCGnaïve patients treated with BCG vs. RF-CHT [19]. Although CR and RFS rates found in this study are lower, we have evaluated patients who likely were at higher risk for recurrence or progression considering two-thirds were BCG-failures or intolerant, possibly explaining the different $\mathrm{CR}$ rates. Moreover, the CRrate was evaluated at 6 months in our study instead of at $\leq 3$ months of follow-up. To our best knowledge, no 
additional studies have investigated RF-CHT effect in CIS patients.

Compared to $\mathrm{BCG}$ alone, our reported $\mathrm{CR}$ rates at 6 months after RF-CHT and the associated recurrence rates are at the better end of the literature-reported range after BCG in treatment naïve CIS patients, with the $\mathrm{CR}$ rate ranging from $65-77 \%$ at $3-5$ months and recurrence rates varying up to $30 \%[34,35]$.

In considering RF-CHT as an alternative to surgery, one should take the risks of potential undertreatment with RF-CHT vs. the impact on quality of life after radical cystectomy into account [28]. The significant morbidity and mortality associated with a radical cystectomy combined with its functional consequences is for many patients the main reason to opt for conservative management. However, 13\% and $18 \%$ of the studied patients eventually had to stop either induction or maintenance RF-CHT instillations due to adverse events, consisting of pain, urgency, frequency and allergic reactions. In comparison to BCG, RF-CHT seems to have a similar quantity of AEs, although the type of AEs differ [19].

Due to the retrospective nature, some limitations to this study exist. The collected data was highly heterogeneous due to randomly missing values and different standards of treatment and follow-up between the participating centres. Despite missing values, the different groups had comparable demographic data. To overcome different disease management per centre, strict definitions were applied to improve reliability and assess results objectively. As a downside, a substantial proportion of the selected patients needed to be excluded from analysis inducing risk of selection bias. Moreover, by setting pathology or combined cystoscopy plus cytology availability as a precondition to analysis, a bias towards higher tumor rates or non-response was created: if solely a cystoscopy or cytology only - showing a negative result - was performed, the patient was excluded from analysis even though it is likely that no significant tumor (i.e. $>$ TaLG) was present. If, on the other hand, a positive result with solely cystoscopy or cytology was found, additional evaluation was performed and the patient - who had a higher likelihood of tumor presence - was included. Therefore, the results presented in this paper might depict a worst-case scenario.

In addition, either pathology or the combination of cystoscopy and cytology was also used to assess the 2-year recurrence rate. Since specificity for cytology and cystoscopy is higher than its sensitivity, the amount of false negative cases is limited whereas the amount of false positive cases might be high [36, 37].
Again, this might have resulted in a higher amount of observed recurrences than the actual amount of recurrences, although most recurrences in our study were pathology-confirmed (17/18). Lastly, since this study was non-randomized, a selection bias with confounding by indication to treat may be present even though analysis of all patients with $\geq 6$ RF-CHT instillations did not yield substantially different results.

\section{CONCLUSIONS}

Intravesical radiofrequency-induced chemohyperthermia showed good results in CIS patients - even if BCG-unresponsive - and avoided radical cystectomy in $78.5 \%$ of cases for at least 3 years with a modest risk of progression. Thus, RF-CHT might prove to be an alternative to cystectomy in selected patients, even in this cohort at high risk of disease progression. Consequently, further comparison of RF-CHT with other techniques of chemohyperthermia and with different bladder-sparing approaches is of great interest.

\section{ACKNOWLEDGMENTS}

\section{Conflict of interest}

B Ayres has received non-financial support from Medical Enterprises Ltd. and speaker fees from Kyowa Kirin and Olympus. R Issa reports grants from Medical Enterprises Ltd., outside the submitted work. JA Witjes and G Lüdecke are advisors for Medical Enterprises Ltd. and JA Witjes additionally for Spectrum, Taris, and BioCanCell; without any financial disclosure or conflict of interest on this manuscript. FJP van Valenberg, A Kajtazovic, G Canepa, J Kilb, KKH Aben, O Nativ, and S Madaan have no financial disclosures or conflicts of interest to report.

\section{REFERENCES}

[1] Comperat E, Larre S, Roupret M, Neuzillet Y, Pignot G, Quintens H, et al. Clinicopathological characteristics of urothelial bladder cancer in patients less than 40 years old. Virchows Arch. 2015;466(5):589-94. PubMed PMID: 25697540.

[2] Dy GW, Gore JL, Forouzanfar MH, Naghavi M, Fitzmaurice C. Global Burden of Urologic Cancers, 1990-2013. Eur Urol. 2017;71(3):437-46. PubMed PMID: 28029399.

[3] Antoni S, Ferlay J, Soerjomataram I, Znaor A, Jemal A, Bray F. Bladder Cancer Incidence and Mortality: A Global Overview and Recent Trends. Eur Urol. 2017;71(1):96-108. PubMed PMID: 27370177.

[4] Kamat AM, Li R, O’Donnell MA, Black PC, Roupret M, Catto JW, et al. Predicting Response to Intravesical 
Bacillus Calmette-Guerin Immunotherapy: Are We There Yet? A Systematic Review. Eur Urol. 2017. PubMed PMID: 29055653.

[5] Gontero P, Sylvester R, Pisano F, Joniau S, Vander Eeckt K, Serretta V, et al. Prognostic factors and risk groups in T1G3 non-muscle-invasive bladder cancer patients initially treated with Bacillus Calmette-Guerin: Results of a retrospective multicenter study of 2451 patients. Eur Urol. 2015;67(1):7482. PubMed PMID: 25043942.

[6] Lamm DL. Carcinoma in situ. Urol Clin North Am. 1992;19(3):499-508. PubMed PMID: 1636234.

[7] Babjuk M, Bohle A, Burger M, Capoun O, Cohen D, Comperat EM, et al. EAU Guidelines on Non-Muscleinvasive Urothelial Carcinoma of the Bladder: Update 2016. Eur Urol. 2017;71(3):447-61. PubMed PMID: 2732 4428.

[8] Chang SS, Bochner BH, Chou R, Dreicer R, Kamat AM, Lerner SP, et al. Treatment of Non-Metastatic MuscleInvasive Bladder Cancer: AUA/ASCO/ASTRO/SUO Guideline. J Urol. 2017;198(3):552-9. PubMed PMID: 2845 6635.

[9] Lamm DL, Blumenstein BA, Crissman JD, Montie JE, Gottesman JE, Lowe BA, et al. Maintenance bacillus Calmette-Guerin immunotherapy for recurrent TA, T1 and carcinoma in situ transitional cell carcinoma of the bladder: A randomized Southwest Oncology Group Study. J Urol. 2000;163(4):1124-9. PubMed PMID: 10737480.

[10] Oddens JR, Sylvester RJ. Chemohyperthermia with Mitomycin-C Compared with Bacillus Calmette-Guerin: A "Hot" Topic. Eur Urol. 2016;69(6):1053-4. PubMed PMID: 26873840.

[11] Griffiths TR, Charlton M, Neal DE, Powell PH. Treatment of carcinoma in situ with intravesical bacillus CalmetteGuerin without maintenance. J Urol. 2002;167(6):2408-12. PubMed PMID: 11992047.

[12] Oddens J, Brausi M, Sylvester R, Bono A, van de Beek $\mathrm{C}$, van Andel G, et al. Final results of an EORTC-GU cancers group randomized study of maintenance bacillus Calmette-Guerin in intermediate- and high-risk Ta, T1 papillary carcinoma of the urinary bladder: One-third dose versus full dose and 1 year versus 3 years of maintenance. Eur Urol. 2013;63(3):462-72. PubMed PMID: 23141049.

[13] Fernandez-Gomez J, Madero R, Solsona E, Unda M, Martinez-Pineiro L, Ojea A, et al. The EORTC tables overestimate the risk of recurrence and progression in patients with non-muscle-invasive bladder cancer treated with bacillus Calmette-Guerin: External validation of the EORTC risk tables. Eur Urol. 2011;60(3):423-30. PubMed PMID: 21621906.

[14] Cambier S, Sylvester RJ, Collette L, Gontero P, Brausi MA, van Andel G, et al. EORTC Nomograms and Risk Groups for Predicting Recurrence, Progression, and Disease-specific and Overall Survival in Non-Muscle-invasive Stage TaT1 Urothelial Bladder Cancer Patients Treated with 1-3 Years of Maintenance Bacillus Calmette-Guerin. Eur Urol. 2016;69(1):60-9. PubMed PMID: 26210894.

[15] Steinberg RL, Thomas LJ, Mott SL, O'Donnell MA. Bacillus Calmette-Guerin (BCG) Treatment Failures with Non-Muscle Invasive Bladder Cancer: A Data-Driven Definition for BCG Unresponsive Disease. Bladder Cancer. 2016;2(2):215-24. PubMed PMID: 27376140. Pubmed Central PMCID: PMC4927860.

[16] Kamat AM, Colombel M, Sundi D, Lamm D, Boehle A, Brausi M, et al. BCG-unresponsive non-muscle-invasive bladder cancer: Recommendations from the IBCG. Nat Rev Urol. 2017;14(4):244-55. PubMed PMID: 28248951.

[17] Liem EI, Crezee H, de la Rosette JJ, de Reijke TM. Chemohyperthermia in non-muscle-invasive bladder cancer: An overview of the literature and recommendations. Int J Hyperthermia. 2016;32(4):363-73. PubMed PMID: 27056069.

[18] van Valenberg H, Colombo R, Witjes F. Intravesical radiofrequency-induced hyperthermia combined with chemotherapy for non-muscle-invasive bladder cancer. Int J Hyperthermia. 2016;32(4):351-62. PubMed PMID: 26905963.

[19] Arends TJ, Nativ O, Maffezzini M, de Cobelli O, Canepa G, Verweij F, et al. Results of a Randomised Controlled Trial Comparing Intravesical Chemohyperthermia with Mitomycin C Versus Bacillus Calmette-Guerin for Adjuvant Treatment of Patients with Intermediate- and High-risk Non-Muscle-invasive Bladder Cancer. Eur Urol. 2016;69(6):1046-52. PubMed PMID: 26803476.

[20] Alfred Witjes J, Hendricksen K, Gofrit O, Risi O, Nativ O. Intravesical hyperthermia and mitomycin-C for carcinoma in situ of the urinary bladder: Experience of the European Synergo working party. World J Urol. 2009;27(3):31924. PubMed PMID: 19234857. Pubmed Central PMCID: PMC2694311.

[21] Jarow JP, Lerner SP, Kluetz PG, Liu K, Sridhara R, Bajorin $\mathrm{D}$, et al. Clinical trial design for the development of new therapies for nonmuscle-invasive bladder cancer: Report of a Food and Drug Administration and American Urological Association public workshop. Urology. 2014;83(2):262-4. PubMed PMID: 24332121.

[22] Lerner SP, Dinney C, Kamat A, Bivalacqua TJ, Nielsen $\mathrm{M}$, O'Donnell M, et al. Clarification of Bladder Cancer Disease States Following Treatment of Patients with Intravesical BCG. Bladder Cancer. 2015;1(1):2930. PubMed PMID: 26807434. Pubmed Central PMCID: PMC4720147.

[23] Di Stasi SM, Giannantoni A, Giurioli A, Valenti M, Zampa G, Storti L, et al. Sequential BCG and electromotive mitomycin versus BCG alone for high-risk superficial bladder cancer: A randomised controlled trial. Lancet Oncol. 2006;7(1):43-51. PubMed PMID: 16389183.

[24] Lee JY, Diaz RR, Cho KS, Lim MS, Chung JS, Kim WT, et al. Efficacy and safety of photodynamic therapy for recurrent, high grade nonmuscle invasive bladder cancer refractory or intolerant to bacille Calmette-Guerin immunotherapy. J Urol. 2013;190(4):1192-9. PubMed PMID: 23648222.

[25] Sternberg IA, Dalbagni G, Chen LY, Donat SM, Bochner $\mathrm{BH}$, Herr HW. Intravesical gemcitabine for high risk, nonmuscle invasive bladder cancer after bacillus CalmetteGuerin treatment failure. J Urol. 2013;190(5):1686-91. PubMed PMID: 23665400.

[26] Skinner EC, Goldman B, Sakr WA, Petrylak DP, Lenz HJ, Lee CT, et al. SWOG S0353: Phase II trial of intravesical gemcitabine in patients with nonmuscle invasive bladder cancer and recurrence after 2 prior courses of intravesical bacillus Calmette-Guerin. J Urol. 2013;190(4):1200-4. PubMed PMID: 23597452. Pubmed Central PMCID: PMC4113593.

[27] Dinney CP, Greenberg RE, Steinberg GD. Intravesical valrubicin in patients with bladder carcinoma in situ and contraindication to or failure after bacillus CalmetteGuerin. Urol Oncol. 2013;31(8):1635-42. PubMed PMID: 22575238. 
[28] Tang DH, Chang SS. Management of carcinoma in situ of the bladder: Best practice and recent developments. Ther Adv Urol. 2015;7(6):351-64. PubMed PMID: 26622320. Pubmed Central PMCID: PMC4647140.

[29] Lammers RJ, Witjes JA, Inman BA, Leibovitch I, Laufer $\mathrm{M}$, Nativ $\mathrm{O}$, et al. The role of a combined regimen with intravesical chemotherapy and hyperthermia in the management of non-muscle-invasive bladder cancer: A systematic review. Eur Urol. 2011;60(1):81-93. PubMed PMID: 2153 1502.

[30] IKNL. https://www.cijfersoverkanker.nl/selecties/Dataset_ 1/img5a8e99c048d5f. Website Integraal Kankercentrum Nederland. 2001-2010; Consulted on 22 Feb 2018. Dutch.

[31] Marcos-Gragera R, Mallone S, Kiemeney LA, Vilardell L, Malats N, Allory Y, et al. Urinary tract cancer survival in Europe 1999-2007: Results of the population-based study EUROCARE-5. Eur J Cancer. 2015;51(15):2217-30. PubMed PMID: 26421824

[32] Shore ND, Boorjian SA, Canter DJ, Ogan K, Karsh LI, Downs TM, et al. Intravesical rAd-IFNalpha/Syn3 for Patients With High-Grade, Bacillus Calmette-GuerinRefractory or Relapsed Non-Muscle-Invasive Bladder Cancer: A Phase II Randomized Study. J Clin Oncol. 2017; 35(30):3410-6. PubMed PMID: 28834453. Pubmed Central PMCID: PMC5648171.

[33] Arends TJ, van der Heijden AG, Witjes JA. Combined chemohyperthermia: 10-year single center experience in
160 patients with nonmuscle invasive bladder cancer. J Urol. 2014;192(3):708-13. PubMed PMID: 24704017.

[34] Koga H, Ozono S, Tsushima T, Tomita K, Horiguchi Y, Usami M, et al. Maintenance intravesical bacillus CalmetteGuerin instillation for Ta, T1 cancer and carcinoma in situ of the bladder: Randomized controlled trial by the BCG Tokyo Strain Study Group. Int J Urol. 2010;17(9):759-66. PubMed PMID: 20604814.

[35] Oosterlinck W, Kirkali Z, Sylvester R, da Silva FC, Busch C, Algaba F, et al. Sequential intravesical chemoimmunotherapy with mitomycin $\mathrm{C}$ and bacillus Calmette-Guerin and with bacillus Calmette-Guerin alone in patients with carcinoma in situ of the urinary bladder: Results of an EORTC genito-urinary group randomized phase 2 trial (30993). Eur Urol. 2011;59(3):438-46. PubMed PMID: 21156335.

[36] Yafi FA, Brimo F, Auger M, Aprikian A, Tanguay S, Kassouf W. Is the performance of urinary cytology as high as reported historically? A contemporary analysis in the detection and surveillance of bladder cancer. Urol Oncol. 2014;32(1):27. e1-6. PubMed PMID: 23410943.

[37] Raitanen MP, Aine R, Rintala E, Kallio J, Rajala P, Juusela $\mathrm{H}$, et al. Differences between local and review urinary cytology in diagnosis of bladder cancer. An interobserver multicenter analysis. Eur Urol. 2002;41(3):284-9. PubMed PMID: 12180229. 